\title{
Mandatory vaccinations: The Canadian picture
}

A $s$ might be expected in Canada, vaccination policies are as diverse as the geography. Most provinces seek to achieve high immunization rates by educating their populations about the benefits of vaccines. Just three have legislated vaccination policies, applying strictly to children about to enrol in school. Ontario and New Brunswick require immunization for diphtheria, tetanus, polio, measles, mumps, and rubella immunization, while Manitoba requires a measles vaccination.

In each case, though, the legislation includes an exemption clause. Essentially, each of the three provinces allows parents to request that their child be exempted from the vaccination requirement on medical or religious grounds, or simply out of conscience. In such instances, in the event of a disease outbreak, unvaccinated children can be excluded from entering a school.

"The exclusion of nonimmunized individuals from entry during an outbreak situation is to protect the public and to contain the outbreak as quickly as possible," Andrew Morrison, spokesperson for the Ontario Ministry of Health and Long-Term Care, writes in an email.

New Brunswick takes a similar approach and it's "unlikely" that the province would ever "enforce mandatory vaccination for the population in general," Danielle Phillips, spokesperson for the province's Department of Health, writes in an email. "That being said, during something like a pandemic event, people who are not immunized might have to be excluded from certain social/ work environments where causing risk to others would be unacceptable."

Phillips adds that if actions ever had to be taken against individuals, they would probably be in the form of isolation, quarantine or directly observed treatment.

For the most part, vaccination compliance rates appear high in most provinces.

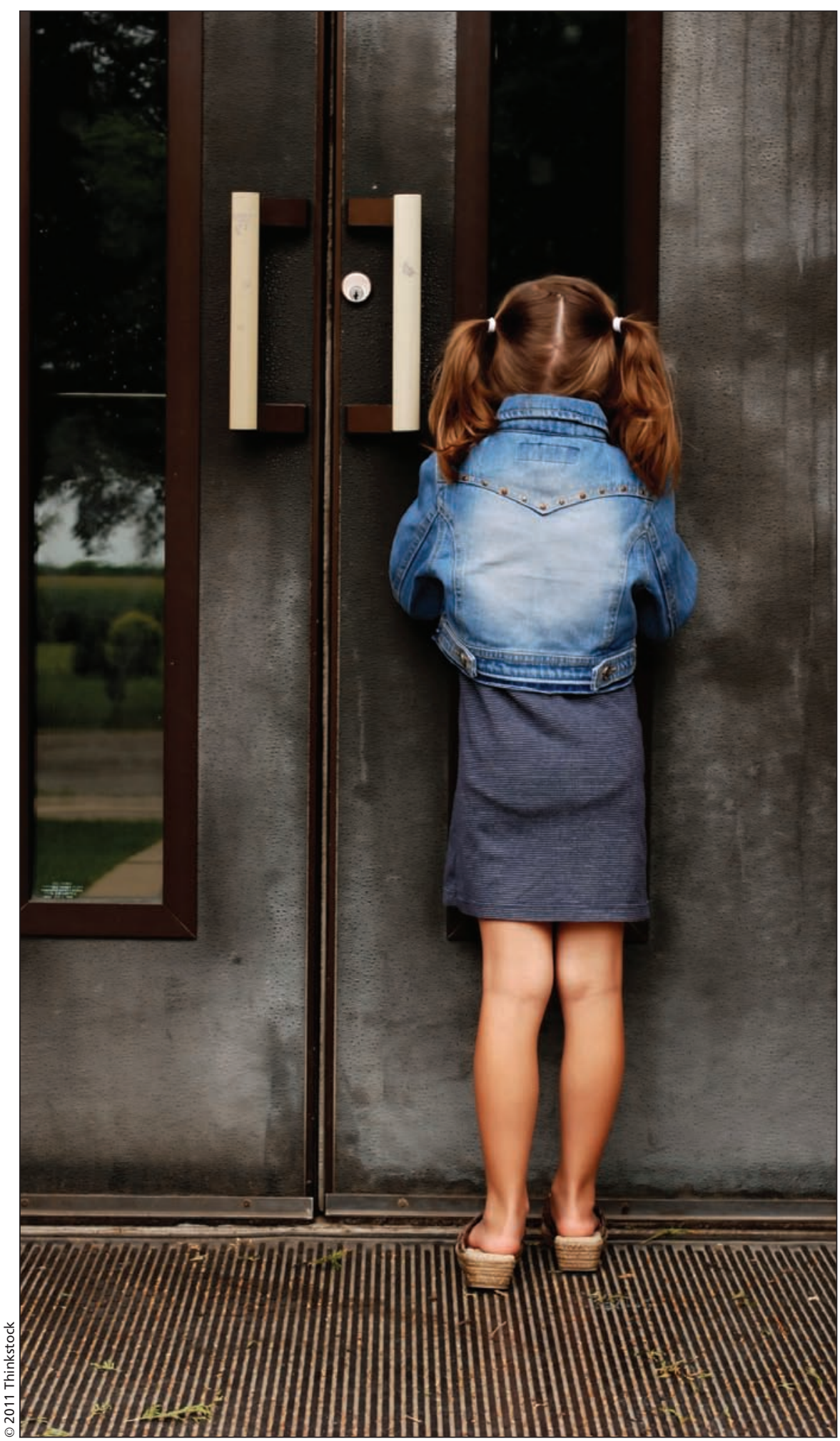

In Ontario, Manitoba and New Brunswick, unvaccinated children can be excluded from entering a school in the event of a disease outbreak. 
In New Brunswick, for example, 93.6\% of children entered kindergarten in the 2008-09 school year with the required vaccinations, Phillips writes.

In Ontario, "the vast majority of school pupils comply with the requirement to report their immunization status to attend school in the province," Morrison writes. In the 2009-2010 school year, $84 \%-92 \%$ of students aged 7 to 17 had been vaccinated. "That means $8 \%$ $16 \%$ of school-aged children either did not report to local health units the appropriate number of required immunizations or have exemption on file," he adds.

Theoretically, noncompliance can result in hefty penalties. In Ontario, failure to vaccinate children can result in a fine of up to $\$ 1000$ (www.e-laws .gov.on.ca/html/statutes/english/elaws _statutes_90i01_e.htm).

Other provinces, such as Alberta, which do not have any form of legislation governing vaccinations, nevertheless retain the authority to preclude students from attending school in the event of a disease outbreak. "Immunization in Alberta is voluntary; therefore no student is denied entrance into a school facility based on their immunization status. However, if there is a case or outbreak of measles in school setting, a child would be excluded from school until two weeks after the last case occurred if he/she is not immunized against measles," the Alberta Ministry of Health writes in an email.

The ministry added that "Alberta has not considered making school immunization mandatory since the immunization rates achieved to date are over $90 \%$ by the time a student leaves grade one."
Vaccination skeptics say there's no need for provinces to move with stricter policies.

In the case of outbreaks, parents should be allowed to determine whether they "are willing to take the risk that their children get that disease, get through it and develop long-term, lifelong immunity," says Edda West, coordinator coordinator of Vaccination Risk Awareness Network (Canada), a not-for-profit educational group. "The parents of the vaccinated children believe their children are totally protected from that disease, so what is the problem? Who is being protected?"

West adds that if vaccination advocates "believe the vaccine works and they're really effective, then the unvaccinated child should pose no problems to anybody."

Advocates counter that the extent to which a vaccine is effective within a population is based on both coverage (the number of people vaccinated), and efficacy of the vaccine within those individuals, which varies.

Vaccine effectiveness, in terms of percentage, ranges from the low seventies and eighties for influenza or pertussis, to the nineties for measles and up to $100 \%$ for human papilloma virus and hepatitis B, says Dr. Ian Gemmill, former chair of the Canadian Coalition of Immunization Awareness and Promotion.

Vaccination policies for health care workers appear equally languorous across the nation. Most provinces do not have legislation in the area, although, in Alberta, all health care workers who deal with infants, prenatal women or in postpartum settings must be protected against rubella. As well, "some private long term care facilities in Alberta have instituted mandatory influenza immunization in the event of an influenza outbreak in that facility," the Ministry of Health and Wellness writes in an email.

Ontario has no plans to proceed with legislation, although the Ontario Ministry of Health and Long-Term Care "is strongly supportive of statements by the National Advisory Committee on Immunization (NACI) which highly recommends that health care workers be immunized," Morrison writes. "In many instances, individual work place policies require health care workers to be immunized against specific diseases as a condition of employment at the facility or institution."

The federal government doesn't appear inclined to step into the fray, noting that vaccination policies, and enforcement therein, fall within provincial jurisdiction.

"The Public Health Agency of Canada supports immunization as an effective means to protect Canadians from infectious diseases, and encourages all Canadians to keep their immunizations up-to-date," Charlene Wiles, media relations advisor for the agency, writes in an email. - Erin Walkinshaw, Ottawa, Ont.

CMAJ 2011. DOI:10.1503/cmaj.109-3992

Editor's note: First of a three-part series on mandatory vaccination 